\title{
Synthesis and Anti-Knock Properties of Furfural Derivatives
}

\author{
Valery E. Tarabanko ${ }^{* a, b}$, \\ Mikhail Y. Chernyak ${ }^{a}$, Konstantin L. Kaygorodova, \\ Nina F. Orlovskaya ${ }^{b}$, Andrey A. Morozov ${ }^{a}$, \\ Alexander A. Kondrasenko ${ }^{a}$ and Yuriy N. Bezborodov ${ }^{b}$ \\ ${ }^{a}$ Institute of Chemistry and Chemical Technology SB RAS \\ FRC "Krasnoyarsk Science Center SB RAS" \\ 50/24 Akademgorodok, Krasnoyarsk, 660036, Russia \\ ${ }^{b}$ Siberian Federal University \\ 79 Svobodny, Krasnoyarsk, 660041, Russia
}

Received 20.02.2016, received in revised form 04.04.2016, accepted 30.05.2016

\begin{abstract}
Research octane numbers (RON) of the furfural diethyl acetal and furfurylamine solutions in straight-run gasoline were measured, and the liner dependences between the solution octane numbers and concentrations of furfural derivatives were found. Blending research octane numbers

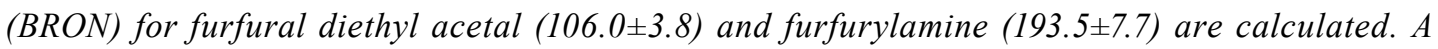
novel method of syntheses of furfural diethylacetal by the direct interaction of the alcohol and the aldehyde is developed. To shift the reaction equilibrium a water vapour from gas phase over the reaction mass is removed by calcium oxide. Oxidative stability of the furfurylamine solutions in straight-run gasoline (test for induction period) was estimated. It corresponds to the GOST 2084-77 conditions at the furfurylamine concentrations less than $5 \mathrm{wt} . \%$ and exceeds value of $1000 \mathrm{~min}$.
\end{abstract}

Keywords: biofuels, furfural diethyl acetal, furfural, furfurylamine, blending research octane number (BRON), straight-run gasoline.

* Corresponding author E-mail address: veta@icct.ru 


\title{
Синтез и антидетонационные свойства производных фурфурола
}

\author{
В.Е. Тарабанько ${ }^{\mathrm{a}, \tilde{0}}$, М.Ю. Черняк ${ }^{\mathrm{a}}$, \\ К.Л. Кайгородов ${ }^{\mathrm{a}}$ Н.Ф. Орловская ${ }^{\tilde{6}}$, \\ А.А. Морозов ${ }^{\text {a }}$, А.А. Кондрасенко ${ }^{\text {a }}$, Ю.Н. Безбородов ${ }^{\sigma}$ \\ ${ }^{a}$ Институт химии и химической технологии СО РАН \\ ФИЦ «Красноярский научный иентр СО РАН» \\ Россия, 660036, Красноярск, Академгородок, 50/24 \\ ${ }^{6}$ Сибирский федеральный университет \\ Россия, 660041, Красноярск, пр. Свободный, 79
}

Исследовательским методом оченены октановые числа растворов диэтилацеталя фурфурола и фурфуриламина в прямогонном бензине и установлены линейные зависимости октанового числа растворов изученных веществ от их концентрации. Рассчитаны

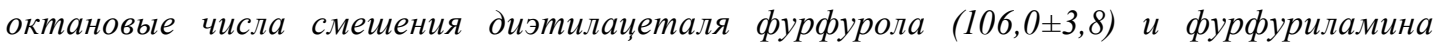

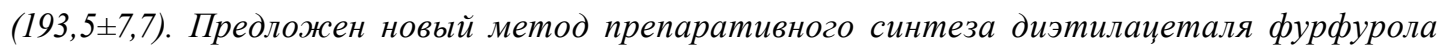
прямым взаимодействием спирта и альдегида. Для смещения равновесия реакции пары воды из газовой фазы над раствором реагирующих веществ удаляются оксидом кальция. Оченена окислительная стабильность растворов фурфуриламина в прямогонном бензине: по показателю «индукционный период» (более 1000 мин) она соответствует требованиям ГОСТ 2084-77 при концентрации фурфуриламина менее 5 мас. \%.

Ключевые слова: биотоплива, фурфурол, диэтилачеталь фурфурола, фурфуриламин, октановое число смешения, прямогонный бензин.

\section{Введение}

Разработка методов получения биотоплив из возобновляемого растительного сырья - интенсивно развивающаяся область химических и биотехнологических исследований, важная перспектива химических технологий будущего. Продукты такого типа получают либо биохимическими методами (этанол, бутанол и др.), либо химическими (продукты пиролиза, гидролиза и др.). Кислотно-каталитические процессы превращения гексозных углеводов характеризуются сравнительно большими скоростями по сравнению с ферментативными и узким набором продуктов (в основном 5-гидроксиметилфурфурол, левулиновая (4-кетопентановая) кислота и их эфиры [1, 2]) по сравнению с процессами пиролиза. Каталитическим гидрированием названных продуктов и их эфиров получают перспективные добавки к бензинам (2,5-диметилфуран, октановое число 119) [3, 4] и дизельным топливам (бутиллевулинат, бутилвалероат).

Биотоплива на основе фурфурола, получаемого кислотно-каталитической конверсией пентозных углеводов, например сельхозотходов травянистых растений, могут быть дешевле древесных отходов, из которых можно получать 5-гидроксиметилфурфурол [5]. Это одна из 
причин активного развития исследований по переработке фурфурола в продукты топливного назначения. Показана возможность синтеза 2-этоксиметилфурана (этилфурфуриловый эфир) с выходом 30-50 \% каталитическим алкилированием фурфурилового спирта и определено его октановое число (ОЧ 110) [6]. По единичным экспериментальным точкам оценена детонационная стойкость фурфурилового спирта (ОЧ 134) [7], пропил- и бутилфурфурилового эфиров (ОЧ 112 и 98 соответственно), ацеталей фурфурола [8,9] и фурфуриламина [10]. Перспективный продукт гидрирования фурфурола, 2-метилфуран (ОЧ 131), в смеси с бензином успешно прошел дорожные испытания [3].

Показаны возможности применения в качестве высокооктановых компонентов кеталей глицерина и арабинозы, несмотря на их очень низкую летучесть $[11,12]$. Хорошо известна антидетонационная присадка монометиланилин (ММА) [13]. Фурановые аналоги таких соединений, например диэтилацеталь и этиленгликольацеталь фурфурола, по температурам кипения попадают в диапазон кипения бензиновых фракций, но изучение их антидетонационных свойств только начато $[8,9]$.

Цель настоящей работы заключается в оценке влияния концентрации производных фурфурола, его диэтилацеталя и фурфуриламина на детонационные свойства прямогонного бензина.

\section{Экспериментальная часть}

В работе использовали фурфурол и фурфуриламин (98 \% основного вещества, Acros Organics). Для определения октанового числа в качестве разбавителя применяли фракцию прямогонного бензина со следующими характеристиками: октановое число по исследовательскому методу 49,0, плотность 0,702 г/мл, массовая доля серы 0,004 \%, температура начала и конца кипения 96 и $185{ }^{\circ} \mathrm{C}$ соответственно, пределы перегонки 10,50 и $90 \%-107,121$ и $155^{\circ} \mathrm{C}$ соответственно. Кривая выкипания бензина представлена на рис. 1.

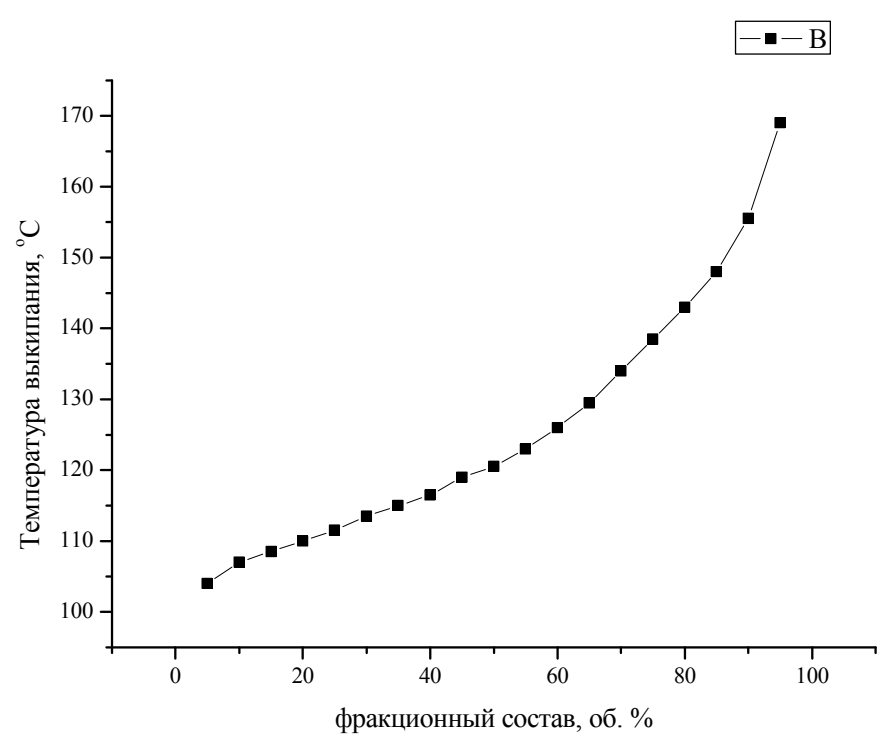

Рис. 1. Кривая выкипания прямогонного бензина при 732 торр

$$
-223-
$$


Диэтилацеталь фурфурола (ДЭАФ) получали двумя способами - взаимодействием фурфурола с ортоэтилформиатом [14] и прямым взаимодействием фурфурола с этанолом. Для смещения равновесия в последнем случае раствор фурфурола в этаноле (1 : 3 моль/моль) выдерживали при комнатной температуре в эксикаторе, на дно которого помещали оксид кальция в качестве водоотнимающего средства, в течение 30-90 сут.

Идентификацию полученных соединений проводили методами ГЖХ-МС (хроматомасс-спектрометр Agilent 7890а с квадрупольным детектором Agilent 5975с) и ЯМР (ЯМРспектрометр Bruker Avance III $600 \mathrm{MHz}$ ) Центра коллективного пользования Красноярского научного центра СО РАН. Октановые числа растворов полученных веществ в прямогонном бензине определяли исследовательским методом на универсальной установке для определения октанового числа, модель Waukesha CFR F1/F2 (США).

Окислительную стабильность растворов ДЭАФ и фурфуриламина определяли на установке SETA AUTO oxidation control unit Stanhope-SETA U.K., model 15450-3 U при $100{ }^{\circ} \mathrm{C}$ и начальном давлении кислорода 700 кПа $\left(20^{\circ} \mathrm{C}\right)$. За индукционный период принимали промежуток времени от момента погружения автоклава в разогретый заполненный маслом термостат до точки перегиба зависимости давления в автоклаве от времени.

\section{Результаты и их обсуждение}

Характеристики прямогонного бензина. Использованная в настоящей работе фракция прямогонного бензина почти не содержит легких фракций и имеет температуры начала и конца кипения 96 и $185^{\circ} \mathrm{C}$ соответственно (рис. 1).

Спектр протонного магнитного резонанса бензина (рис. 2) позволяет оценить содержание протонов ароматических углеводородов в нем, которое составляет 2,0 \%. Грубые оценки массового содержания ароматических соединений в бензине можно сделать на основании простейшей модели двухкомпонентного состава ксилол - октан, и эта оценка дает около 8 мас. \% ароматических веществ. Параксилол в бензине регистрируется также хромато-масс-

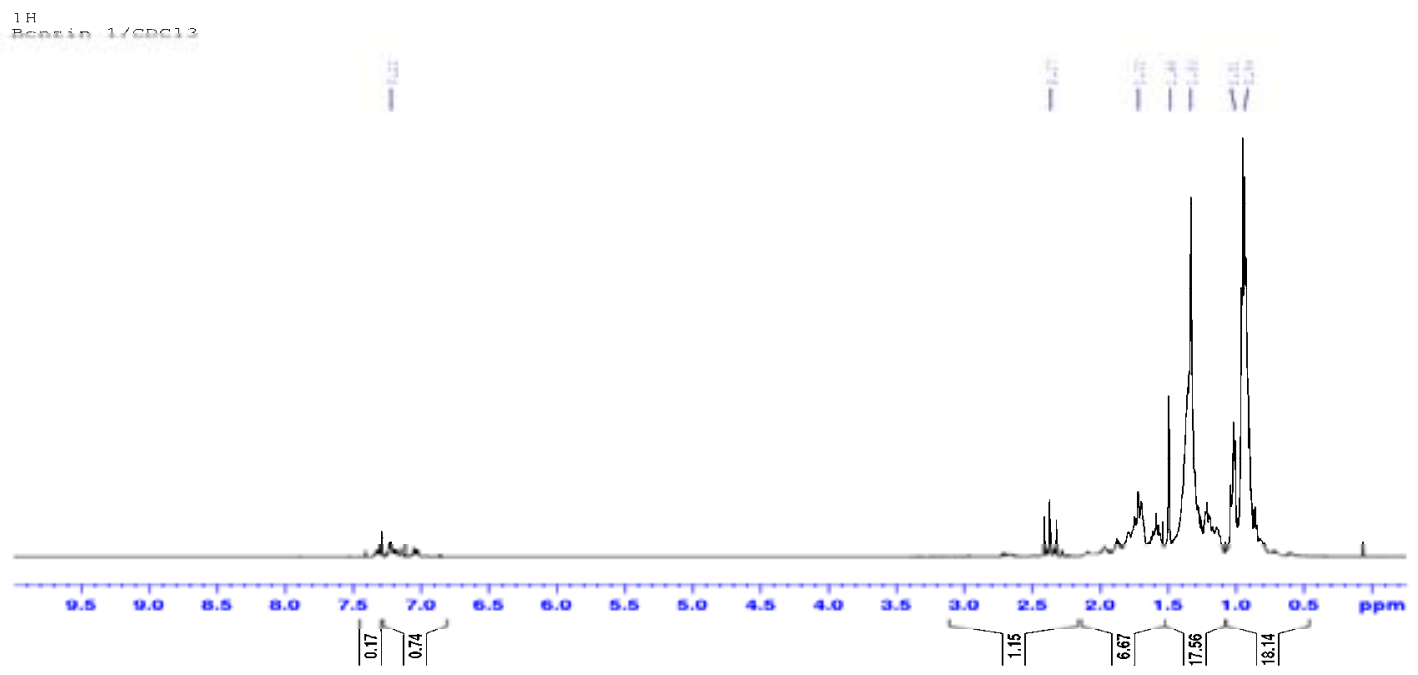

Рис. 2. Спектр ПМР прямогонного бензина 
спектрометрически. В качестве основных компонентов на хроматограмме идентифицируются гексаны (время удерживания 1,8-2,2 мин), гептаны (3,0-3,9 мин), октаны (6,2-7,4 мин) и деканы (10,9-16,0 мин).

Низкое содержание ароматических соединений, а также легких фракций, характеризующихся сравнительно высокими октановыми числами, определяют малое октановое число использованного в работе бензина - 49 пунктов, а также стабильность последнего в работе благодаря его невысокой летучести. Низкое октановое число и стабильность бензина, используемого в качестве разбавителя изученных соединений, минимизируют ошибки определения октановых чисел растворов и расчета детонационной стойкости растворенных веществ.

Детонационная стойкость фурановых производных. На рис. 3 представлены зависимости октанового числа растворов фурфуриламина и диэтилацеталя фурфурола от концентрации этих веществ. Эти зависимости практически линейны и описываются регрессионными уравнениями (1) и (2) для фурфуриламина и ДЭАФ соответственно:

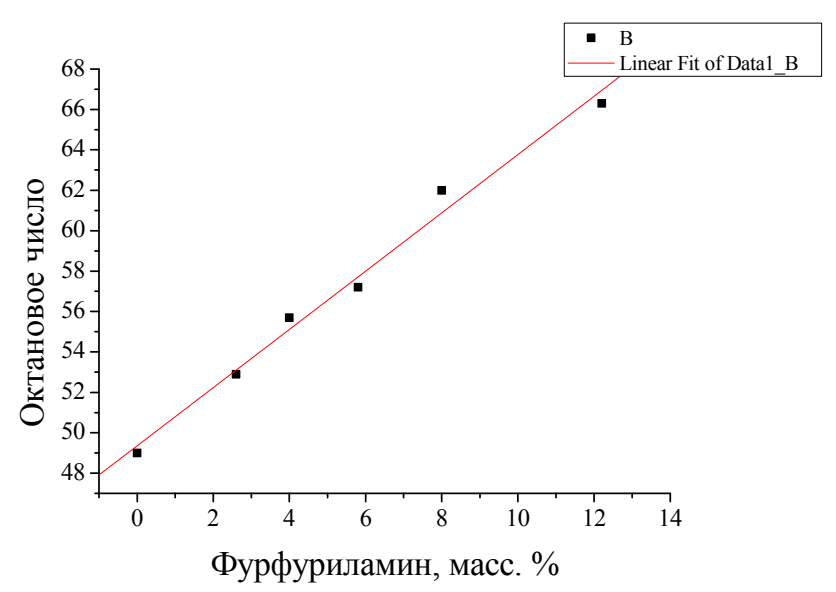

a

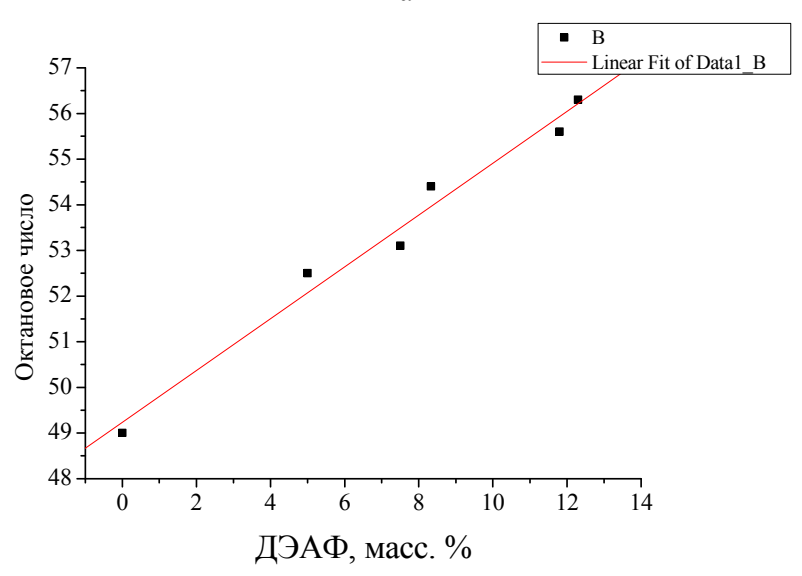

6

Рис. 3. Зависимости октанового числа растворов фурфуриламина (а) и диэтилацеталя фурфурола (б) от их массовой концентрации в бензине 


$$
\begin{aligned}
& Y=A+B X=(49,3 \pm 0,54)+(144,1 \pm 8,1) X \\
& Y=A+B X=(49,2 \pm 0,35)+(56,8 \pm 4,1) X
\end{aligned}
$$

где $\mathrm{Y}$ - октановое число раствора, $\mathrm{X}$ - концентрация исследуемого вещества в мас. долях единицы, А и В - коэффициенты уравнения. В скобках указаны также стандартные отклонения для значений коэффициентов А и В. Коэффициенты корреляции R равны 0,994 и 0,990, а стандартные отклонения $\mathrm{SD}_{\mathrm{Y}}-0,78$ и 0,42 для уравнений (1) и (2) соответственно.

Физический смысл линейных зависимостей (1) и (2) заключается в аддитивности октанового числа растворов $\mathrm{RON}_{\mathrm{sol}}$ в пределах точности эксперимента:

$$
\mathrm{RON}_{\mathrm{sol}}=\left(\mathrm{m}_{\mathrm{g}} * \mathrm{RON}_{\mathrm{g}}+\mathrm{m}_{\text {furf }} * \mathrm{BRON}_{\text {furf }}\right) /\left(\mathrm{m}_{\text {furf }}+\mathrm{m}_{\mathrm{g}}\right)
$$

где $\mathrm{RON}_{\mathrm{g}}$ и $\mathrm{BRON}_{\text {furf }}$ - октановые числа бензина и добавки соответственно. Отсюда следует

$$
\operatorname{RON}_{\text {sol }}=\operatorname{RON}_{\mathrm{g}} *\left(1-\left(\mathrm{m}_{\text {furf }} /\left(\mathrm{m}_{\text {furf }}+\mathrm{m}_{\mathrm{g}}\right)\right)\right)+\mathrm{BRON}_{\text {furf }} * \mathrm{~m}_{\text {furf }} /\left(\mathrm{m}_{\text {furf }}+\mathrm{m}_{\mathrm{g}}\right)
$$

или

$$
\mathrm{Y}=\mathrm{A}(1-\mathrm{X})+\mathrm{BX}=\mathrm{A}+(\mathrm{B}-\mathrm{A}) \mathrm{X}
$$

где $\mathrm{X}$ - концентрация компонента, в мас. долях, $\mathrm{Y}$ - октановое число раствора, $\mathrm{A}=\mathrm{RON}_{\mathrm{g}}$ и $\mathrm{B}=\mathrm{BRON}_{\text {furf }}$.

Интерполяция зависимостей (1) - (2) на 100-процентную концентрацию фуранового компонента дает значения октановых чисел смешения 193,4 для фурфуриламина и 106 для диэтилацеталя фурфурола, но не предоставляет прямой возможности формально оценить ошибки этих величин. Для расчета стандартного отклонения величин октановых чисел компонентов с помощью простейших формул метода наименьших квадратов достаточно переписать уравнение (5), используя в качестве аргумента концентрацию бензина $\mathrm{X}^{\prime}=1-\mathrm{X}$ :

$$
\mathrm{Y}=\mathrm{A}+(\mathrm{B}-\mathrm{A}) \mathrm{X}=\mathrm{A}+(\mathrm{B}-\mathrm{A})\left(1-\mathrm{X}^{\prime}\right)=\mathrm{B}+(\mathrm{A}-\mathrm{B}) \mathrm{X}^{\prime},
$$

где В и А - октановые числа фуранового компонента и бензина соответственно.

Обработка экспериментальных данных по уравнению (6) дает следующие результаты для фурфуриламина (7) и диэтилацеталя фурфурола (8):

$$
\begin{aligned}
& Y=(193,5 \pm 7,7)-(144,1 \pm 8,1) X^{\prime} \\
& Y=(106,0 \pm 3,8)-(56,8 \pm 4,1) X^{\prime}
\end{aligned}
$$

т.е. значения октановых чисел и их стандартные отклонения для фурфуриламина и диэтилацеталя фурфурола описываются уравнениями

$$
\begin{aligned}
& \text { BRON }_{\text {furfurylamine }}=193,5 \pm 7,7 \text { и } \\
& \text { BRON }_{\text {acetal }}=106,0 \pm 3,8 .
\end{aligned}
$$

Таким образом, полученные результаты показывают, что зависимости октановых чисел растворов фурфуриламина и диэтилацеталя фурфурола в прямогонном бензине от концентра- 
Таблица 1. Зависимость индукционного периода кривых поглощения кислорода растворами фурфуриламина от его концентрации

\begin{tabular}{|l|c|c|c|c|c|c|}
\hline \multicolumn{1}{|c|}{ Концентрация фурфуриламина } & 0 & 0,1 & 0,3 & 1,0 & 2,0 & 5,0 \\
\hline Начало поглощения кислорода, мин & $>4000$ & $>5000$ & 4700 & 1900 & 1200 & 520 \\
\hline $\begin{array}{l}\text { Индукционный период по ГОСТ } \\
\text { 4039-88, мин }\end{array}$ & $>5000$ & $>5000$ & $>5000$ & 2900 & 1850 & 960 \\
\hline
\end{tabular}

ции линейны и позволяют вычислить октановые числа смешения этих веществ, в пределах точности эксперимента совпадающие с ранее сделанными оценками [8]. Значительные различия полученного значения октанового числа фурфуриламина $(193,5 \pm 7,7)$ и измеренной ранее величины (126士2) [10] могут быть связаны с разной природой бензинов-разбавителей, использованных в работах $[9,10]$, в первую очередь почти двукратным различием их октановых чисел (49 и 92,9 соответственно).

Окислительная стабильность растворов фурфуриламина и диэтилацеталя фурфурола. В табл. 1 представлены результаты изучения окислительной стабильности растворов фурфуриламина в прямогонном бензине. Установлено, что она соответствует требованиям ГОСТ 2084-77 (900-1200 мин для бензинов с ОЧ более 90). Индукционный период кривых поглощения кислорода растворами фурфуриламина возрастает с 960 до 5000 мин и более при снижении концентрации компонента с 5 до 0,3 мас. \%. Индукционный период для 5\%-го раствора диэтилацеталя фурфурола составляет 1030 мин. Окислительная стабильность растворов фурфуриламина с концентрацией менее 5 мас. \% по показателю «индукционный период» (более 1000 мин) соответствует требованиям ГОСТ 2084-77.

В табл. 1 приведены данные по времени начала поглощения кислорода в процессе испытаний. Эти величины также характеризуют окислительную стабильность растворов, они находятся в интервале 520-5000 мин и более для изученных растворов фурфуриламина.

Таким образом, разнообразные фурановые производные, получаемые в конечном счете из возобновляемого растительного сырья, ацетали, аминопроизводные и простые эфиры можно рассматривать как перспективные высокооктановые компоненты бензинов. Наиболее выраженными антидетонационными свойствами среди фурановых производных обладает фурфуриламин.

\section{Список литературы}

1. Xiao Sh., Liu B., Wang Y.M., Fang Z.F., Zhang Z. Efficient conversion of cellulose into biofuel precursor 5-hydroxymethylfurfural in dimethyl sulfoxide-ionic liquid mixtures. Bioresource Technology 2014. Vol. 151. P. 361-366.

2. Тарабанько В.Е., Черняк М.Ю., Кузнецов Б.Н., Захарова О.В. Исследование процессов кислотно-каталитической дегидратации углеводов в присутствии бутанола при умеренных температурах. Химия растительного сырья 2002. № 2. C. 5-15. [Tarabanko V. E., Chernyak M.Yu., Kuznetsov B.N., Zakharova O.V. Investigation of the acid-catalyzed conversion in the presence of butanol at moderate temperatures. The chemistry of plant raw material 2002, No. 2, p. 5-12. (In Russ.)]

$$
-227-
$$


3. Roman-Leshkov Y., Barret C.J., Liu Z.Y., Dumesic J.A. Production of dimethylfuran for liquid fuels from biomass-derived carbohydrates. Nature 2007. Vol. 447. P. 982-985.

4. Alonso D.M., Bond J.Q., Dumesic J.A. Integrated catalytic conversion of $\gamma$-valerolactone to liquid alkenes for transportation fuels. Green Chem. 2010. Vol. 12. P. 1110-1114.

5. Варфоломеев С.Д., Моисеев И.И., Мясоедов Б.Ф. Энергоносители из возобновляемого сырья. Химические аспекты. Вестник Российской академии наук 2009. Т. 79. № 7. С. $595 .-$ 604. [Varfolomeev S.D., Moiseev I.I., Myasoedov B.F. Energy carriers from renewable raw materials. Herald of the Russian Academy of Science 2009. V. 79. No. 7, p. 595-604. (In Russ.)]

6. Lange J.P., Evert van der Heide, Jeroen van Buijtenen, Price R. Furfural - a promising platform for lignocellulosic biofuels. ChemSusChem 2012. Vol. 5. P. 150-166.

7. Resasco D.E., Sitthisa S., Faria J., Prasomsri T., Ruiz M.P. Furfurals as chemical platform for biofuels production. In: Heterogeneous catalysis in biomass to chemicals and fuels. Research Signpost. India 2011. P. 234.

8. Тарабанько В.Е., Черняк М.Ю., Морозов А.А., Кайгородов К.Л., Безбородов Ю.Н., Орловская Н.Ф., Надейкин И.В. Новые высокооктановые компоненты бензинов из растительного сырья. Журн. СФУ, Химия 2014. Т. 7. № 1. С. 31-35. [Tarabanko V.E., Chernyak M.Yu., Morozov A.A., Kaygorodov K.L., Bezborodov Y.N., Orlovskaya N.F. and Nadeykin I.V. New Gasoline Components of High Octane Number Made of Plant Raw Materials. Journal of Siberian Federal University. Chemistry 2014. V. 7 (1 ), p. 31-35. (In Russ.)].

9. Тарабанько В.Е., Черняк М.Ю., Симакова И.Л., Кайгородов К.Л., Безбородов Ю.Н., Орловская Н.Ф. Антидетонационные свойства производных фурфурола. Журн. прикладной химии 2015. T. 88, вып. 11. C. 1563-1567. [Tarabanko V.E., Chernyak M.Yu., Simakova I.L., Kaigorodov K.L., Bezborodov Yu.N. and Orlovskaya N. F. Antiknock Properties of Furfural Derivatives. Russ. J. Appl. Chem. 2015, Vol. 88, No. 11, pp. 1563-1567. (In Russ.)].

10. Gouli S., Lois E., Stournas S. Effects of Some Oxygenated Substitutes on Gasoline Properties, Spark Ignition Engine Performance, and Emissions. Energy \& Fuels. 1998. V. 12. No. 5. P. $918-924$.

11. Максимов А.Л., Нехаев А.И., Рамазанов Д.Н., Ариничева Ю.А., Дзюбенко А.А., Хаджиев С.Н. Получение оксигенатных высокооктановых компонентов топлив на основе полиолов растительного происхождения. Нефтехимия 2011. T. 51. № 1. С. 62-69. [Maksimov A.L., Nekhaev A.I., Ramazanov D.N., Arinicheva Yu.A., Dzyubenko A.A., and Khadzhiev S.N. Preparation of HighOctane Oxygenate Fuel Components from Plant-Derived Polyols. J. Petroleum Chemistry 2011. V. 51. No. 1, p. 61-62. (In Russ.) ].

12. Максимов А.Л., Нехаев А.И., Рамазанов Д.Н. Простые эфиры и ацетали - перспективные продукты нефтехимии из возобновляемого сырья (обзор). Нефтехимия 2015. Т. 55. № 1. С. 3-24. [Maksimov A.L., Nekhaev A.I., Ramazanov D.N. Ethers and Acetals, Promising Petrochemicals from Renewable Sources. J. Petroleum Chemistry 2015. V. 55. No. 1, p. 3-24. (In Russ.) ].

13. Сыроежко А.М., Бегак О.Ю., Макурина Г.С. Влияние различных высокооктановых добавок на антидетонационные свойства бензинов. Журн. прикладной химии 2004. Т. 77. Вып. 6. C. 1006-1002. [Syroezhko, A.M., Begak, O.Y., and Makurina, G.S. Russ. Effect of Various HighOctane Additives on Antiknock Quality of Gasolines. Russ. J. Appl. Chem. 2004, vol. 77, No. 6, pp. 1006-1000. (In Russ.)]. 
14. Потапов В.М. Органикум. Практикум по органической химии. Т.2 М.: Мир. 1979. С. 64. [Potapov, V.M., Organikum. Praktikum po organicheskoi khimii (Organicum: Practical works on Organic Chemistry), Moscow: Mir, 1979. p.64. (In Russ.)]. 